\title{
A influência do Programa Bolsa Família nas práticas alimentares das famílias do Território do Marajó, Pará, Brasil
}

\author{
The influence of Bolsa Família Program on food practices of the families of Territory of \\ Marajo, Pará, Brazil
}

\author{
E. C. do Nascimento ${ }^{1 *}$; B. E. V. da Cruz ${ }^{2}$; M. F. Calvi ${ }^{3}$; J. P. L. de Carvalho ${ }^{1}$; C. \\ C. dos Reis ${ }^{1}$; D. L. Gomes ${ }^{1}$ \\ ${ }^{1}$ Núcleo de Extensão em Desenvolvimento Territorial, Universidade Federal do Pará, CEP 66077-005, Belém-Pará, \\ Brasil \\ ${ }^{2}$ Departamento de Filosofia e Ciências Humanas, Universidade do Estado do Pará, CEP 66.050-540, Belém-Pará, \\ Brasil \\ ${ }^{3}$ Faculdade de Engenharia Florestal/Departamento de Floresta, Universidade Federal do Pará, CEP 68372-040, \\ Altamira-Pará, Brasil \\ *elcioncosta@gmail.com
}

(Recebido em 09 de abril de 2016; aceito em 19 de abril de 2016)

\begin{abstract}
Este trabalho demonstra a influência do Programa Bolsa Família nos hábitos alimentares das famílias do território do Marajó, PA. Programas de transferência de renda têm se constituído como ferramenta efetiva no acesso à educação, à saúde e na garantia da segurança alimentar em países Latino-Americanos e do Caribe. Utilizando abordagem qualitativa e os procedimentos da entrevista semiestruturada, buscou-se informações que permitissem analisar a influência do Programa Bolsa Família nas práticas e nos hábitos alimentares das famílias marajoaras. Observou-se que o benefício tem impacto positivo no acesso a uma melhor alimentação, com maior variedade, tanto em quantidade quanto em qualidade e na elevação do padrão de vida dos entrevistados. Porém, o benefício teve pouca relevância no consumo de verduras e hortaliças, indicando a necessidade de atividades educativas juntos aos beneficiários, sobre a importância de dietas mais variadas e ricas em nutrientes provenientes de produtos naturais como frutas, verduras e vegetais, tornando as famílias agentes diretos nas ações de combate à insegurança alimentar no Território do Marajó.
\end{abstract}

Palavras chaves: Hábitos alimentares, Programas Sociais, Consumo alimentar

This paper demonstrate the influence of the Bolsa Família Program in the eating habits of families of the Territory of Marajó, State of Pará, Brazil. Cash transfer programs have been constituted as an effective tool in access to education, health and ensuring food security in Latin countries American and the Caribbean. Using a qualitative approach and procedures of semi-structured interviews and free list, it sought information which could allow the analyse of the influence of the Bolsa Família Program on practices and eating habits of marajoaras families. It was observed that the benefit has a positive impact on access to better food, with more variety, both in quantity and quality and on lifting the life standard of respondents. However, the benefit has little relevance in the consumption of vegetables, indicating a need for educational activities with the beneficiaries on the importance of a more varied diet and rich in nutrients from natural products such as fruits and vegetables, making families direct agents in actions to combat food insecurity in the Marajo Territory.

Keywords: Eating habits, Social programs, Food consumption

\section{INTRODUÇÃO}

Os hábitos alimentares são socialmente desenvolvidos. A partir do conceito de habitus, que segundo Bourdieu [1], são "disposições socialmente construídas que, enquanto estruturas estruturadas e estruturantes, constituem o princípio gerador e unificador do conjunto das práticas e das ideologias características de um grupo social", cada grupo social tem sua definição do que é considerado alimento e comida, pois nem tudo que é comestível, que seja nutricionalmente válido, é socialmente aceito como comível $[2,3]$. 
Peña e Molina [4] afirmam que essas escolhas e definições recebem diversos tipos de influências, como: os saberes locais, os costumes, a cultura e a disponibilidade e acessibilidade desses recursos e alimentos. Estes fatores, somados com as experiências gustativas, as condições sociais, ambientais, econômicas e pelas adaptações necessárias, refletem na construção de práticas alimentares singulares aceitas por um determinado grupo, contribuindo para a aquisição de certos hábitos particulares $[5,6,7,8,9]$.

Esses hábitos são assimilados ao longo da vida do indivíduo à medida que são expostos a esses costumes, necessários para a vida em uma específica sociedade, à medida que este, através da prática, internaliza aquilo que a família, escola, amigos, igreja, meios de comunicação, entre outros, lhe introduzem [7, 10]. Segundo Stones [9], essa assimilação é primordial para que o indivíduo possa envolver-se com "sucesso em uma série de práticas sociais", sendo reconhecido como membro daquela sociedade.

Canesqui [5] afirma que a base da formação das práticas alimentares é a família, pois é no âmbito familiar que o indivíduo tem o primeiro contato com o alimento. É no seio da família que as primeiras regras, costumes e normas, referentes ao ato de comer, são repassados e assimilados pelo indivíduo [11, 12].

Na Amazônia, segundo Adams et al. [13] e Murrieta [14], a prática alimentar se concentra, principalmente em populações ribeirinhas, no binômio peixe e mandioca. Prática caracterizada por influência do meio ambiente, pelas técnicas produtivas, pelos costumes e pelos recursos naturais disponíveis, instituindo um modo de vida singular "amazônico", que possibilita o acesso a uma alimentação de qualidade e em quantidade regulares [7]. Estes fatores são essenciais para a garantia da segurança alimentar e nutricional - SAN de um grupo, povo ou sociedade [15], tendo em vista que situações impeditivas de acesso a esses recursos e que dificultem a produção de alimentos, estão entre as principais causas de situações de fome e de insegurança alimentar [16].

Porém, esses hábitos podem ser modificados ao longo do tempo. As influências, o contato e o acesso a outras culturas e populações têm impacto nas mudanças alimentares de uma sociedade [17]. A mídia, os comerciais e as mudanças sociais e demográficas têm seu grau significativo de influência [4], assim como, aspectos econômicos e sociais [1]. Essas mudanças, segundo Góes [18], ocorrem devido ao caráter adaptativo do ser humano, variando a medida que as condições de existências vão se modificando ao longo do tempo. Dessa maneira, o estudo dos hábitos alimentares, segundo Santos [17], "diz muito sobre a educação, a civilidade e a cultura dos indivíduos", conhecer as formas de obtenção e preparo dos alimentos, assim como, a maneira que esses hábitos se desenvolvem, se perpetuam ou são deixados de lado, colaboram na compreensão da dinâmica de uma sociedade $[2,17,18]$.

Neste contexto, os programas de transferência de renda têm influência direta nas práticas ou hábitos alimentares de grupos ou sociedades. $\mathrm{O}$ acesso a um padrão de consumo mais elevado pelas famílias beneficiárias modifica, de certa forma, as práticas alimentares locais, positiva ou negativamente, dependendo da situação e das escolhas dos próprios beneficiários. Programas de transferência direta de renda condicionada têm como objetivos o alívio imediato da pobreza e da extrema pobreza em curto prazo, elevar o investimento no capital humano em longo prazo e, principalmente, a quebra do ciclo de transmissão da pobreza entre gerações [19, 20, 21, 22, 23].

No Brasil, o Programa Bolsa Família - PBF surge da unificação de outros quatro programas: Bolsa Escola (Ministério da Educação), Bolsa Alimentação (Ministério da Saúde), Auxílio Gás (Ministério das Cidades) e Cartão Alimentação (Ministério de Segurança Alimentar) como estratégia de combate à desigualdade social, à extrema pobreza e à fome [24, 25].

No mesmo direcionamento outros programas de transferência de renda são exemplos na América Latina e Caribe (Progresa/Oportunidades, México; Familias em Accion, Colombia; Uruguayan/Uruguai) visando, da mesma forma que o PBF, o alívio imediato da pobreza e, principalmente, a quebra do ciclo de transmissão desta entre as gerações, gerando impactos significativos na redução do trabalho infantil, no consumo de alimentos e no acesso a serviços de saúde e educação através das condicionalidades [19, 20, 21, 22, 26].

No Brasil, segundo Silva et al [27], a desnutrição é fortemente ligada à baixa renda, o que prejudica o acesso à alimentação em quantidade e qualidade suficiente, de acordo com o 
conceito de segurança alimentar proposto pela Lei Orgânica de Segurança Alimentar e Nutricional (LOSAN) Lei $n^{\circ}$ 11. 346/06, que institui a Política Nacional de Segurança Alimentar [15].

O PBF, em 2015, beneficiou quase 14 milhões de famílias, com benefícios médios de R\$ 163,57. O valor total transferido pelo governo federal em benefícios às famílias atendidas ultrapassou os $\mathrm{R} \$ 2$ bilhões de reais, representando cerca de $0,4 \%$ do Produto Interno Bruto PIB do país. Porém, segundo Neri, Vaz e Souza [28], além dos impactos sociais, o PBF representa impacto significativo na atividade econômica, uma vez que para cada $R \$ 1,00$ investido no programa, o mesmo representa um aumento de $\mathrm{R} \$ 1,78$ no PIB, possuindo uma relação custo $\mathrm{x}$ benefício amplamente benéfica na economia do país.

No Estado do Pará, segundo o Relatório de Informações Sociais do Brasil [29], existem 1.376.705 famílias cadastradas no Cadastro Único para Programas Sociais do Governo Federal (CADÚnico), famílias que possuem renda de até meio salário mínimo por pessoa ou renda total de até três salários mínimos [30]. Desse total, 913.985 famílias recebem o benefício do PBF. No Território do Marajó são 99.619 famílias cadastradas e 78.573 famílias beneficiárias do programa, representando $7 \%$ e $8,6 \%$, respectivamente [31], movimentando um montante de $\mathrm{R} \$$ 17.617.230,00 em 2015.

Nesta perspectiva, este trabalho tem como objetivo refletir a influência que o PBF tem sobre as práticas alimentares das famílias beneficiárias do Território da Cidadania do Marajó.

\section{MATERIAL E MÉTODOS}

O Programa Territórios da Cidadania foi criado em 2008 com o objetivo de promover o desenvolvimento econômico e universalizar programas básicos de cidadania por meio de uma estratégia de desenvolvimento territorial sustentável. Sua implementação ocorreu respeitando o contexto específico de cada território, a diversidade e as dinâmicas territoriais existentes [32]. No Pará existem, atualmente, oito Territórios da Cidadania: Marajó, Baixo Tocantins, Nordeste Paraense, Sudeste Paraense, Sul do Pará/Alto Xingu, Transamazônica, Baixo Amazonas e BR163. O Território do Marajó foi o último criado no Pará, nascendo de diversos debates durante a construção do Plano de Desenvolvimento Territorial do Arquipélago do Marajó [33].

O Território do Marajó é formado por 16 municípios que compõem a Mesorregião do Marajó [34]. Esta mesorregião tem área territorial de $104.140 \mathrm{~km}^{2}$ (Tabela 1), distribuída em três microrregiões geográficas (MRG): Arari, Furos de Breves e Portel (Figura 1). As duas primeiras compreendem municípios inseridos integralmente no Arquipélago do Marajó. Já a MRG de Portel abrange municípios com sedes em áreas continentais, na porção sul/sudoeste da mesorregião. 


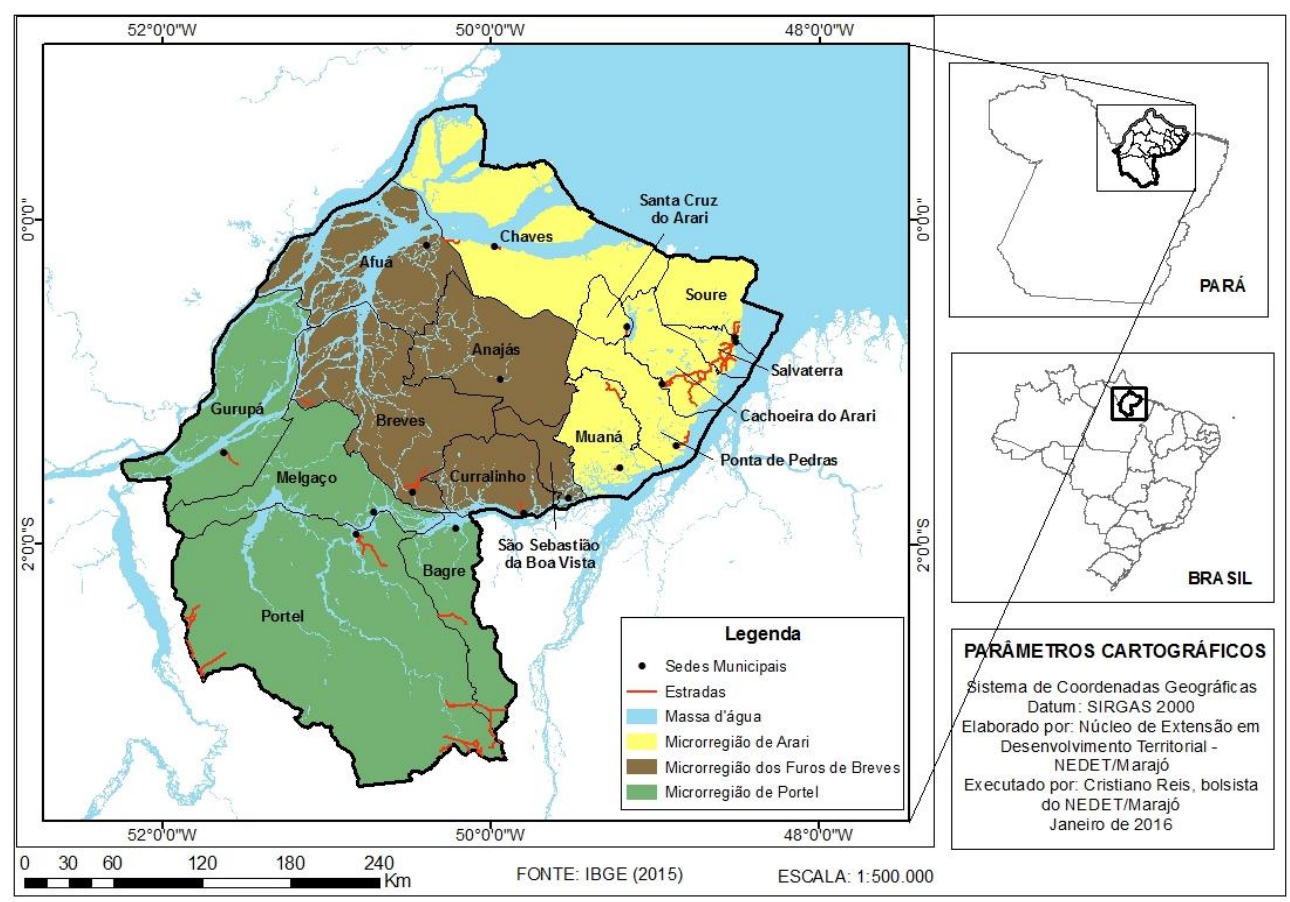

Figura 1 - Mapa do Território do Marajó e suas microrregiões

Tabela 01 - Municípios que compõem a Mesorregião do Marajó.

\begin{tabular}{lc}
\hline Microrregiões / Municípios & Área $\left.\mathbf{( k m}^{\mathbf{2}}\right)$ \\
\hline Microrregião do Arari & $\mathbf{2 8 . 9 5 0}$ \\
Cachoeira do Arari & 3.102 \\
Chaves & 13.085 \\
Muaná & 3.766 \\
Ponta de Pedras & 3.365 \\
Salvaterra & 1.044 \\
Santa Cruz do Arari & 1.075 \\
Soure & 3.513 \\
Microrregião dos Furos de Breves & $\mathbf{3 0 . 0 9 4}$ \\
Afuá & 8.373 \\
Anajás & 6.922 \\
Breves & 9.550 \\
Curralinho & 3.617 \\
São Sebastião da Boa Vista & 1.632 \\
Microrregião de Portel & $\mathbf{4 5 . 0 9 6}$ \\
Bagre & 4.397 \\
Gurupá & 8.540 \\
Melgaço & 6.774 \\
Portel & 25.385 \\
\hline TOTAL & $\mathbf{1 0 4 . 1 4 0}$ \\
\hline
\end{tabular}

Fonte: IBGE [34]

Foram realizadas visitas em cinco municípios do Território do Marajó (Cachoeira do Arari, Salvaterra, Curralinho, Melgaço e Portel), no período de agosto a novembro de 2015 (Figura 2). Foram entrevistadas 50 famílias beneficiárias do Programa Bolsa Família, sendo 10 em cada município; as entrevistas foram feitas, em sua maioria, no espaço destinado ao atendimento do Programa nas Secretarias Municipais de Assistência Social. Objetivou-se, com esses municípios, alcançar famílias pertencentes às três microrregiões do Território do Marajó, obtendo maior representatividade territorial nas informações. Os dados foram coletados por meio de entrevista semiestruturada e registro de áudio seguindo as recomendações de Poulain e 
Proença [35], listagem livre [36] e questionário sobre consumo de diferentes grupos alimentares [37].

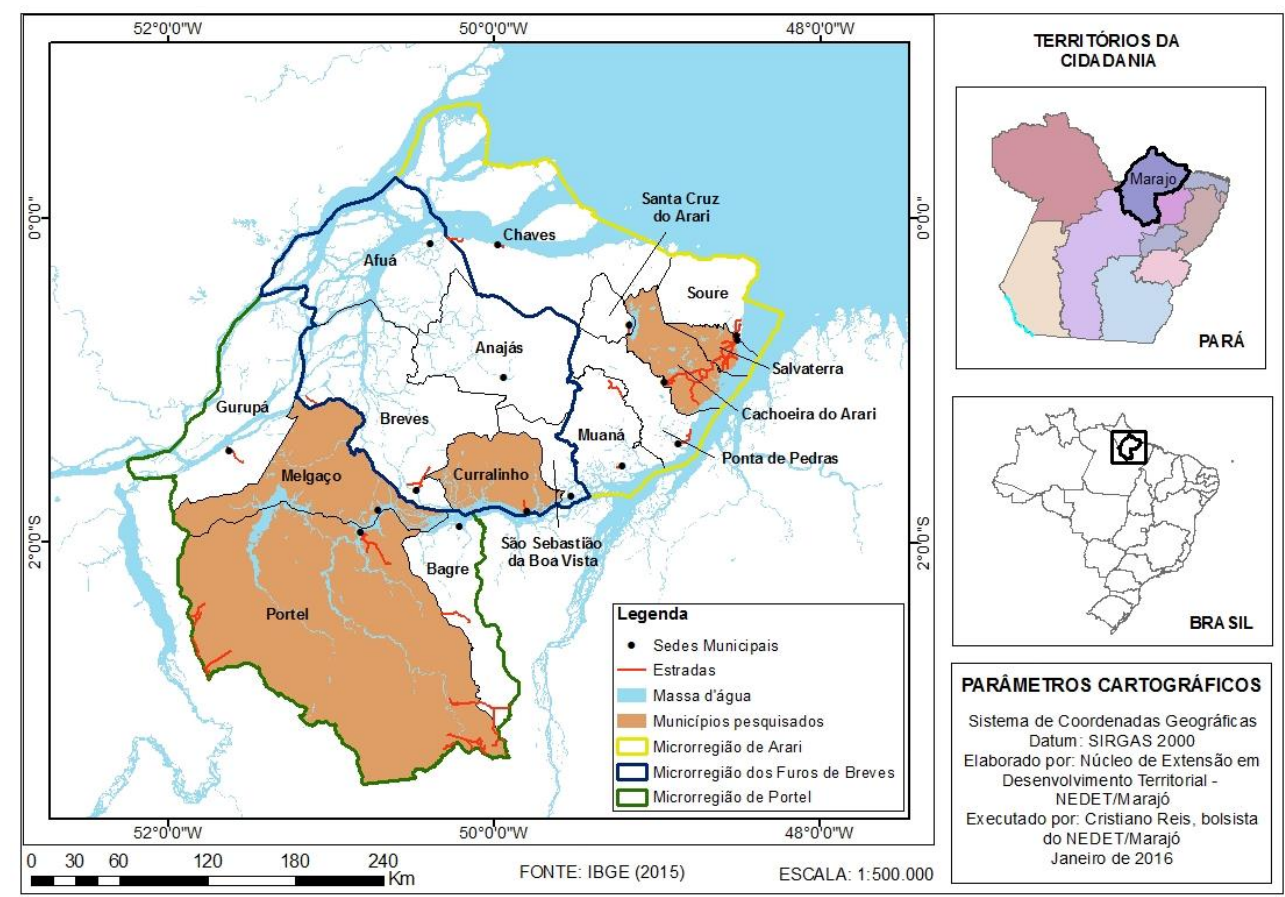

Figura 2 - Municípios onde a pesquisa foi realizada

As entrevistas semiestruturadas tiveram por objetivo estimular o entrevistado a falar abertamente, porém sem perder o foco da pesquisa e nem seu direcionamento. Buscou-se criar um ambiente confortável, no qual a famílias entrevistadas pudessem expressar-se livremente, sem as limitações criadas por um questionário. As conversas foram gravadas, anotadas e posteriormente transcritas para favorecer a análise. O roteiro foi dividido em três seções: a) dados socioeconômicos e hábitos alimentares; b) informações sobre (in)segurança alimentar e; c) informações sobre o destino dado aos recursos recebidos do Programa Bolsa Famílias, com dois focos, geral (gastos realizados) e específico, gastos com alimentação.

A listagem livre parte do princípio de que os produtos primeiramente citados, e com maior frequência, são os que têm maior importância cultural [36]. Esta técnica foi utilizada para identificar os alimentos mais consumidos e, portanto, mais importantes na alimentação diária das famílias do Território do Marajó e as mudanças nas práticas alimentares ao longo do tempo, na medida do possível a ser observado.

O questionário sobre o consumo de diferentes grupos alimentares foi utilizado com o intuito de observar mudanças na alimentação das famílias marajoaras após sua inserção no PBF. Foram incluídos 15 grupos alimentares: cereais (arroz, farinha, pão, tapioca, macarrão), tubérculos (mandioca, batata doce, batata), hortaliças, biscoitos (recheados, água e sal), frutas, sucos, feijão, carne (vermelha, galinha, peixe e porco), óleos e gorduras (manteiga, margarina, óleos), leite e derivados (iogurte, queijos, creme de leite), ovos, açúcar, frituras, refrigerante e comida processada (salsicha, enlatados e comidas "prontas") e cada grupo foi avaliado utilizando a seguinte pergunta: "O consumo de [tipo de alimento] após o início do recebimento do benefício? Para a resposta foram colocadas três possíveis alternativas: 1) aumentou; 2) diminuiu e 3) não houve mudanças. A metodologia da listagem livre foi utilizada concomitantemente ao questionário para observar qual alimento, entre as opções dadas, teve maior ou menor alteração na alimentação das famílias marajoaras. Em grupos mais amplos como o das frutas, hortaliças, sucos e comidas processadas apenas foi pedido aos entrevistados que mencionassem qual fruta, suco ou comida processada era mais consumido pelos membros da família.

A renda, proveniente dos benefícios do Governo Federal, aparece como a principal fonte de renda fixa das famílias. Além do benefício do Programa Bolsa Família, a aposentadoria e o 
seguro defeso foram citados pelas famílias entrevistadas. Das 50 famílias, 18 (36\%) declararam ter alguém da família que recebe a aposentadoria e 13 (26\%) recebiam o seguro-defeso, um benefício financeiro temporário fornecido aos pescadores durante o período do defeso. A maioria dos entrevistados foi mulheres $(73 \%)$ com renda inferior a 01 (um) salário mínimo (36\%), idade entre 40 e 50 anos, respectivamente $25 \%$ e $21 \%$, e com baixo nível de escolaridade (Ensino Fundamental incompleto,75\%), tendo estudado até a $4^{\text {a }}$ serie ou $5^{\circ}$ ano (29\%). O número de pessoas por unidade familiar ficou na faixa de 2 a 4 pessoas $(52 \%)$.

\section{RESULTADOS E DISCUSSÃO}

O recurso proveniente dos programas de transferência direta de renda, como o PBF, apresenta uma importância relevante no que tange às estratégias desenvolvidas dentro da unidade familiar, principalmente, pelo seu caráter mensal e fixo e, portanto, confiável. A liberdade na forma de investimento do recurso, a autonomia na tomada de decisão sobre em que, como, e onde aplicar esse recurso, acarreta melhoras no bem-estar social das famílias beneficiárias $[38,39]$. De maneira geral, conforme observado na pesquisa, o recurso é destinado para suprir as necessidades mais imediatas da unidade familiar, mas principalmente à compra de material escolar e de uniforme para as crianças, à aquisição de equipamentos eletrônicos e outros bens (geladeira, televisão, ventilador, bicicleta, entre outros) e, principalmente, à aquisição de alimentos.

\footnotetext{
"pra roupa, pra remédio, pro alimento, pra tudo eu tiro desse dinheiro, pra me manter, eu e meus filhos... (Ribeirinha, Portel).

"quando chega o tempo do meu benefício, eu venho, "arrecebo" [recebo] compro meu pirão, né, arroz, feijão, carne, frango... (Pescador, Melgaço)
}

Castro et al. [40] observaram situação semelhante em estudo sobre percepções da sociedade brasileira sobre o PBF; a renda proveniente do programa proporciona a compra de "mais alimentos", "mais coisas para a casa" e "mais material escolar". Para o IBASE [41], a alimentação também aparece como principal destino dado ao benefício recebido pelas famílias, em $87 \%$ das situações, o gasto com material escolar (46\%) e vestuário (37\%) aparecem logo em seguida. Estes gastos visam o "melhor interesse" dos familiares, obedecendo, sempre, as questões estratégicas determinadas pelos próprios beneficiários.

Esta característica aponta que a renda proveniente do PBF possibilita o acesso a um padrão de consumo mais elevado pelas famílias beneficiárias, possibilitando a compra de bens, anteriormente, não acessíveis devido à falta de uma renda fixa. Essa realidade, segundo os entrevistados, reflete na qualidade de vida das famílias, tendo em vista que após o recebimento do benefício "ficou mais fácil pra conseguir as coisas", "o benefício ajudou na compra de outros alimentos", "ajuda na complementação da alimentação'. Save the children [39] relata a mesma situação no oeste e sudeste africano, ao observar que o recurso recebido do PTCR possibilita não somente uma melhora na qualidade de vida e na alimentação, mas proporciona um bemestar social ao possibilitar a aquisição de bens não alimentares (roupas, sapatos, graxas de sapato) refletindo num conforto e na vontade das crianças em participarem das escolas.

Esse padrão mais elevado é refletido na alimentação das famílias locais, as quais podem, através do benefício e da autonomia no gasto do recurso, ter acesso a alimentação mais variada e de melhor qualidade. Observou-se um aumento significativo na quantidade e na variedade dos alimentos adquiridos pelas famílias (Figura 3). Pode-se observar um maior consumo de proteína tanto de origem animal: carnes (58\%), ovos (50\%) e leites e derivados (50\%) quanto de origem vegetal: Feijão $(72 \%)$. O consumo de Cereais aparece na segunda posição com um aumento de $66 \%$ entre os entrevistados, principalmente, de arroz, farinha e macarrão. 


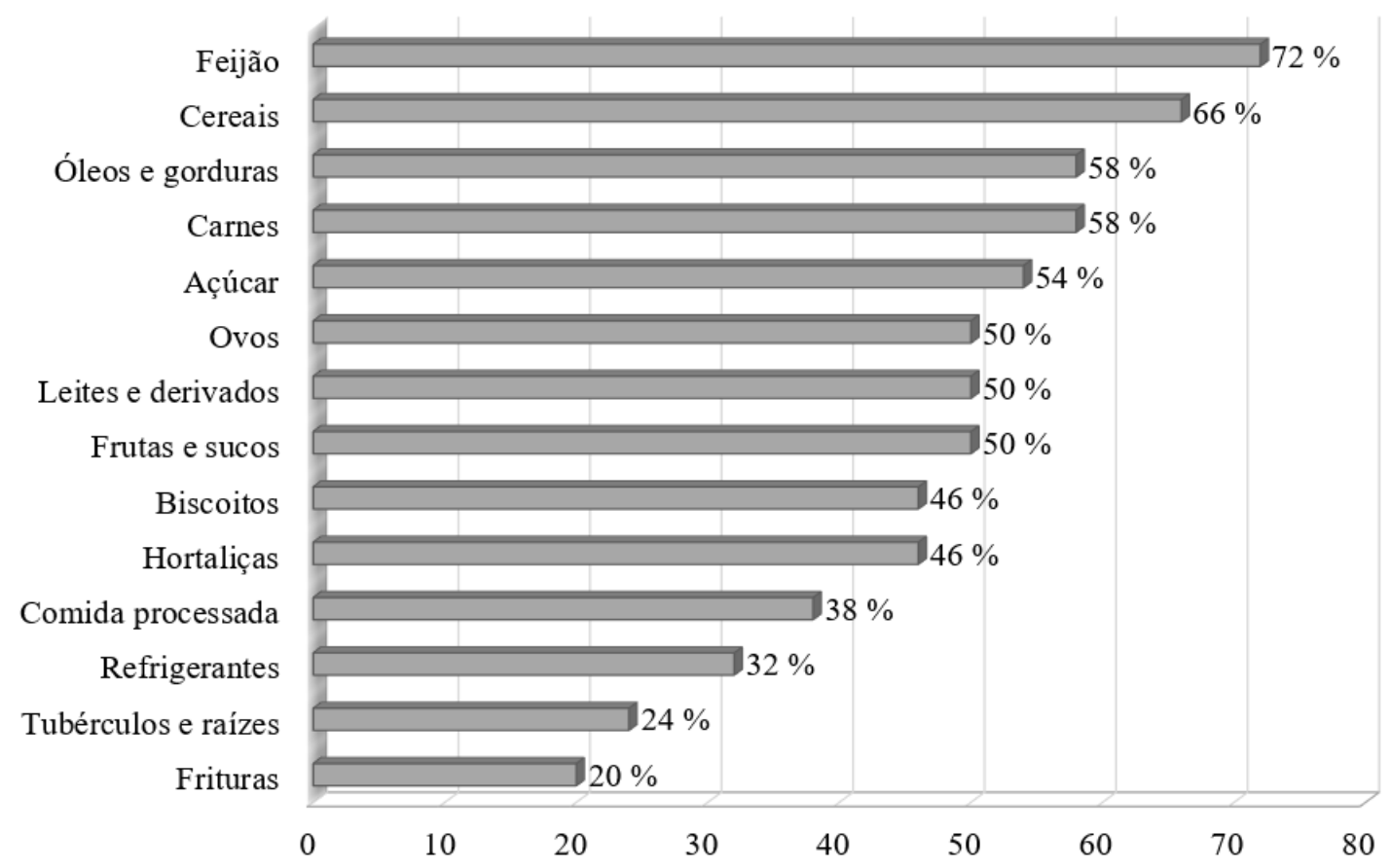

Figura 3 - Influência do Programa Bolsa Família na alimentação das famílias Marajoaras.

Fonte: Pesquisa de campo.

Esse consumo foi observado nas principais refeições do dia, principalmente no almoço, considerado a refeição mais importante pelas famílias locais, devido à necessidade de "ser uma refeição mais completa" - completa no sentido de maior quantidade. Durante as entrevistas, o termo quantidade foi muito utilizado para descrever saciedade, pois ocorrendo o almoço em um horário intermediário, meio do dia, é dele que as famílias tiram as energias para o trabalho e para as demais tarefas do dia. Barbosa [2] utiliza o termo sustância para referir-se a esse aporte energético, necessário para trabalhar, que sustenta ao longo do dia. Ainda segundo Barbosa [2], essa importância é acrescida pela "sensação de saciedade" promovida por essa refeição.

O maior consumo de feijão e arroz nas práticas alimentares das famílias marajoaras pode ser relacionado a "hábitos alimentares compartilhados e socialmente sancionados pela população brasileira" [2]. Neste contexto, existem práticas alimentares que são características comuns ao longo da população brasileira, consequentemente, pode ser observada nas diferentes regiões do país, inclusive no Território do Marajó. Essa mistura do arroz e feijão, segundo Canesqui [42], figura como "itens absolutamente indispensáveis", considerados elementos básico de uma alimentação. O prolongamento da saciedade, segundo Canesqui [43], provocado pelo consumo do feijão, pela sustância e pelos nutrientes existentes nesse alimento, corroboraram para considerá-lo indispensável aos brasileiros e, também, às famílias Marajoaras, como observado nesta pesquisa.

"antes assim, eu não sabia o que era comer um feijão, comer um arroz, um macarrão, uma comida temperada com uma cebola, um óleo, agora, assim, já consigo comprar” (Agricultora, Melgaço).

O consumo de frutas $(50 \%)$ e hortaliças $(46 \%)$ apresentou variação menor, uma vez que o consumo desses alimentos não sofre influência direta do benefício, pois, segundo os entrevistados, as frutas são "produzidas" localmente, ou seja, suas aquisições provêm diretamente da unidade familiar, dos quintais e das áreas no entorno das propriedades. Apesar do autoconsumo, poucas famílias afirmaram incluir com frequência frutas, verduras e hortaliças nas refeições diárias, demonstrando a necessidade de atividades educativas junto aos beneficiários, que aborde a importância de uma dieta variada, que incluam esses produtos. Hoddinott e Skoufias [21] observaram situação diferente entre os beneficiários do programa Progresa (México), onde o consumo de frutas e verduras teve um aumento significativo devido 
à existência de atividades educativas sobre práticas alimentares saudáveis junto as famílias beneficiárias, demonstrando a importância de uma dieta rica e variada em vitaminas e nutrientes.

As taxas de proteína e cereais observadas não destoam muito das recomendações de Philippi et al. [44] em seu trabalho de adaptação da pirâmide alimentar Americana à realidade alimentar Brasileira (Figura 4). Segundo Philippi et al [44], a base da alimentação ( $1^{\circ}$ nível) consiste nos cereais, seguido ( $2^{\circ}$ nível) das frutas e hortaliças, em seguida ( $3^{\circ}$ nível) vem as proteínas e por último ( $4^{\circ}$ nível $)$ as gorduras, doces e açúcares.

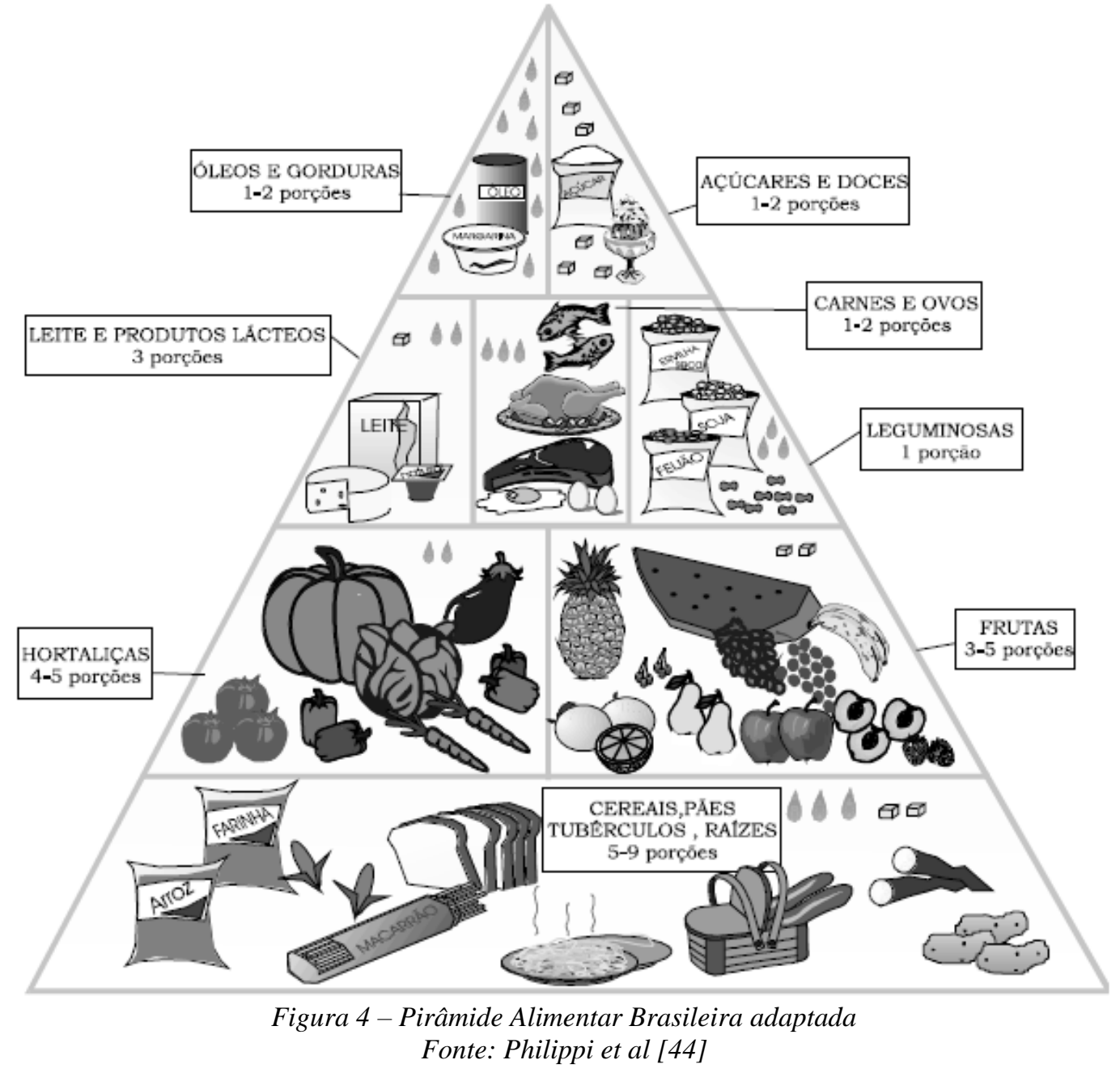

Podemos observar que os cereais (arroz), leguminosas (feijão), grãos (milho), tubérculos e raízes (mandioca, macaxeira) constituem parte importante nas práticas alimentares das famílias marajoaras, sendo a base nas refeições, pois são os alimentos que dão "força" para o trabalho, e sua produção é destinada tanto para o autoconsumo quanto para complementação da renda familiar, assim como, nas relações de vizinhança (trocas).

\footnotetext{
“macaxeira, eu não gosto de vender, só tiro pra comer [...] quando dá bem esse negócio de jerimum, milho, maxixe e cana, quando dá, assim, mais "avortado", aí dá pra gente vender um pouco [...] o milho, o feijão a gente sempre tem, troca por ali por um cafezinho, uma fruta, uns trocados $[\ldots]$ assim vamos levando (Agricultora, Portel).
}

A variação no consumo de açúcar (54\%) e óleos e gorduras (58\%) foi elevada. O consumo desses alimentos (açúcares, doces, sal e alimentos ricos e cálcio), segundo Philippi et al. [44], deve ser moderado. O consumo de comidas processadas ricas em sódio, apesar de alta (38\%), não apresentou índices tão elevados quanto os observados por Bem Lignani et al. (2010) [37] de 
$(57,1 \%)$, porém muitas famílias, durante as entrevistas, comentaram o consumo de: sardinhas em conservas, salsichas, carnes enlatadas e de macarrão instantâneo, demonstrando um aparecimento constante desses alimentos nas refeições, embora dissessem que "não houve diferença" no consumo acarretado pelo recebimento do benefício. Esse aumento da inserção desses alimentos nas práticas alimentares das famílias locais ocorre devido ao baixo custo desses produtos em relação aos alimentos naturais (frutas e verduras), da praticidade e da grande aceitação por parte, principalmente, das crianças e dos jovens.

O consumo de doces e biscoitos é elevado e foi, constantemente, relacionado a um passado de dificuldades e de baixo poder aquisitivo. Foi comum, durante as entrevistas, as famílias admitirem comprar determinado produto, pois na infância, seus pais, não tinham condições financeiras de adquirir e, nos dias de hoje, com uma renda melhor, acesso a crédito e maior confiabilidade nos mercados locais, buscam proporcionar um padrão de vida aos seus filhos que não puderem usufruir. Save the children [39] observou situação semelhante em famílias beneficiárias de programas de renda na África, onde os gastos foram direcionados especialmente à alimentação, assim como, em produtos não-alimentares, objetivando preencher necessidades voltadas ao convívio social e obtenção de status social, devido ao padrão de vida mais elevado, possível somente "nos dias de hoje", com a obtenção mais elevada e estável.

\section{CONCLUSÃO}

Os programas de transferência condicionada de renda influenciam diretamente nas práticas alimentares locais, uma vez que possibilitam uma ascensão social em relação ao aumento do poder aquisitivo dos beneficiários. No que concerne às mudanças nas práticas alimentares, o recebimento do benefício proporcionou o acesso a uma alimentação mais variada e em maior quantidade, embora, às vezes, não suficiente para durar o mês inteiro. Os beneficiários tiveram mais acesso a produtos "nos dias de hoje" que "nos tempos anteriores" tinham mais dificuldade com: proteína de origem animal (derivados do leite e, principalmente, carne vermelha e frango); proteína de origem vegetal (feijão) e um maior aporte no consumo de cereais (arroz, macarrão, farinha), fontes de carboidratos, alimentos essenciais no fornecimento da energia necessária para a condução das atividades desenvolvidas na localidade: agricultura, pesca e extrativismo.

A renda, proveniente dos benefícios, proporcionou um aumento no padrão de consumo das famílias, as quais puderem acessar produtos tanto alimentares quanto não alimentares que antes não era possível, devido à renda baixa e instável. Porém o benefício acarretou o aumento no consumo de produtos de baixo teor nutricional (doces, biscoitos, açucares, óleos e gorduras) e pouca relevância no consumo de verduras e hortaliças, indicando a necessidade de atividades educativas juntos às famílias beneficiárias, sobre a importância de dietas mais variadas e ricas em nutrientes, provenientes de produtos naturais como frutas, verduras e vegetais.

\section{AGRADECIMENTOS}

Agradecemos ao Ministério do Desenvolvimento Agrário - MDA, através da Secretaria de Desenvolvimento Territorial - SDT e ao Conselho Nacional de Desenvolvimento Científico e Tecnológico - CNPq pelo auxílio financeiro.

\section{REFERÊNCIA BIBLIOGRÁFICA}

1. Bourdieu P. A economia das trocas simbólicas / Pierre Bourdieu; introdução, organização e seleção Sergio Micele. São Paulo: Perspectiva, 2009.

2. Barbosa L. Feijão com arroz e arroz com feijão: o Brasil no prato dos brasileiros. Horizontes Antropológicos, Porto Alegre. 2007; 13(28): 87-116. doi: 10.1590/S0104-71832007000200005.

3. Woortmann EF. Padrões tradicionais e modernização: comida e trabalho entre camponeses teutobrasileiros. In: Menasche, R. (org.) A agricultura familiar à mesa: saberes e práticas da alimentação no Vale do Taquari. Porto Alegre: Editora da UFRGS, 2007. 
4. Peña M, Molina V. Food based dietary, guidelines and health promotion in Latin America. Pan American Health Organization. Institute of Nutrition of Central America and Panama - INCAP, 1999.

5. Canesqui AM. Antropologia e alimentação. Revista Saúde Pública. São Paulo. 1988; 22 (3): 207-216. doi: 10.1590/S0034-89101988000300007.

6. Castro J. de Geografia da fome. O dilema brasileiro: pão ou aço. 10 ed. São Paulo: Editora Brasiliense, 1967.

7. Maciel ME. Cultura e alimentação ou o que têm a ver os Macaquinhos de Koshima com BrillatSavarin? Horizontes antropológicos, Porto Alegre, 2001; 7(16): 145-156. doi: 10.1590/S010471832001000200008 .

8. Setton MGJ. A teoria do habitus em Pierre Bourdieu: uma leitura contemporânea. Revista Brasileira de Educação. 2002; 20: 60-70. doi: 10.1590/S1413-24782002000200005

9. Stones R. Habitus. In: (Org.) Scott, J. Sociologia: conceitos-chave. Rio de Janeiro: Zahar, 2010.

10. Woortmann EF. A comida como linguagem. Habitus. 2013; 11(1): 5-17.

11. Mintz SW. Comida e Antropologia: uma breve revisão. Revista Brasileira de Ciências Sociais. 2001; 16(47): 31-41. doi: 10.1590/S0102-69092001000300002.

12. Pacheco SSM. O hábito alimentar enquanto um comportamento culturalmente produzido. In: (Org.) Freitas, MCS, Fontes, GA, Oliveira, N. Escritas e narrativas sobre alimentação e cultura. Salvador: EDUFBA, 2008.

13. Adams C, Murrieta RSS, Sanches RA. Agricultura e Alimentação em Populações Ribeirinhas das Várzeas do Amazonas: novas perspectivas. Ambiente \& Sociedade. 2005; 03(1): 1-22. doi: 10.1590/S1414-753X2005000100005.

14. Murrieta RSS. Dialética do sabor: alimentação, ecologia e vida cotidiana em comunidades ribeirinhas da Ilha de Ituqui, Baixo Amazonas, Pará. Revista de Antropologia. São Paulo. 2001; 44(2): 39-88,. doi: 10.1590/S0034-77012001000200002.

15. Brasil. Lei $\mathrm{n}^{\circ} 11.346$, de 15 de setembro de 2006.

16. Bentes ES. Segurança alimentar nutricional no Pará: situação atual e perspectivas. Belém: UNAMA, 2003.

17. Santos RA. A alimentação e seu lugar na história: os tempos da memória gustativa. Revista da Academia Paranaense de Letras. 2005; 51:165-188

18. Góes JAW. Hábitos alimentares: globalização ou diversidade? In: (Org.) Freitas, MCS, Fontes, GA, Oliveira, N. Escritas e narrativas sobre alimentação e cultura. Salvador: EDUFBA, 2008.

19. Attanasio O, Mesnard A. The impact of a conditional cash transfer Programme on consumption in colombia. Centre for the evaluation of development policies: the institute for fiscal studies, 2005.

20. Borraz F, Gonzalez N. Impact of the Uruguayan Conditional Cash Transfer Program. Cuadernos de Economía. 2009; 46 (134): 243-271. doi: 10.4067/S0717-68212009000200006

21. Hoddinott J, Skoufias E. The impact of PROGRESSA on food consumption. Food Consumption and Nutrition Division: Discussion paper. n 150: 1-30, 2003.

22. Osorio RG, Souza PHG. O Bolsa Família depois do Brasil Carinhoso: uma análise do potencial de redução da pobreza extrema. IPEA: Nota técnica, n 14, 2012.

23. Paes-sousa R, Santos LMP, Miazaki E. Effects of a conditional Cash Transfer Programme on child nutrition in Brazil. Bull World Health Organ. 2011; 89: 496-503. doi:10.2471/BLT.10.084202

24. Lindert K. Brazil: Bolsa Familia Program - Scaling-up Cash Transfers for the Poor. MfDR Principles in Action: Sourcebook on Emerging Good Practices. Executive Sumary. 2005. Disponível em: <http://www.mfdr.org/sourcebook/6-1Brazil-BolsaFamilia.pdf>. Acesso em: 20 out. 2015.

25. Santos LMP, Pasquim EM, Santos SMC. Programas de transferência de renda no Brasil: um estudo multidimensional da implementação do Bolsa Escola, Bolsa Alimentação e Cartão Alimentação. Ciências \& Saúde coletiva. 2011; 16 (3): 1821-1834. doi: 10.1590/S1413-81232011000300018.

26. Behrman JR, Parker SW, Todd PE. Long-term impacts of the oportunidades conditional cash transfer program on rural youth in Mexico. Discussion papers // Ibero America Institute for Economic Research. 2005; 122: 1-55.

27. Silva et al. Programa Bolsa Família e Segurança Alimentar das Famílias Beneficiárias: Resultados para o Brasil e Regiões. In: Brasil. Ministério do Desenvolvimento Social e Combate à Fome. Avaliação de políticas e programas do MDS: resultados: Bolsa Família e Assistência Social. I Ministério do Desenvolvimento Social e Combate à Fome; Secretaria de Avaliação e Gestão da Informação - Brasília, DF: MDS; SAGI, 2007.

28. Neri MC, Vaz FM, Souza PHG. Efeitos macroeconômicos do programa bolsa família: uma análise comparativa das transferências sociais. In: Campello, T, Neri, MC. (org.). Programa Bolsa Famílias: uma década de inclusão e cidadania. Brasília: Ipea, 2013. 
29. Brasil. Relatórios de Informações Sociais: Brasil. Ministério do Desenvolvimento Social e Combate a MDS, $2016 \mathrm{a}$ Disponível em: <<http://aplicacoes.mds.gov.br/sagi/RIv3/geral/relatorio.php〉> Acessado em 15 fev. 2016.

30. Brasil. Cadastro Único. Ministério do Desenvolvimento Social e Combate a Pobreza - MDS, $2016 \mathrm{~b}$. Disponível em: <http://www.mds.gov.br/bolsafamilia/cadastrounico> Acessado em: 15 fev. 2016

31. Brasil. Relatórios de Informações Sociais: RI Bolsa Família e Cadastro Único. Ministério do Desenvolvimento Social e Combate a Pobreza - MDS, 2016c. Disponível em: <<http://aplicacoes.mds.gov.br/sagi/RIv3/geral/index.php〉> Acessado em 15 fev. 2016.

32. Brasil. Territórios da Cidadania. 2016d. Disponível em: $<$ http://www.territoriosdacidadania.gov.br/dotlrn/clubs/territriosrurais/xowiki/oprograma>>. Acessado em 22 fev. 2016.

33. Piraux M, Assis WS, Rodrigues VC, Silva NNM, Alves JW. Um olhar sobre a diversidade dos Colegiados dos Territórios da Cidadania. Novos Cadernos NAEA 2013; 16(1): 101-124. doi: $10.5801 / \mathrm{S} 21797536$.

34. Ibge. Cidades. Disponível em: <http://www.cidades.ibge.gov.br/xtras/uf.php?lang=\&coduf=15\&search=para>. Acesso em: 10 jul. 2105.

35. Poulain J, Proença RPC. Reflexões metodológicas para o estudo das práticas alimentares. Revista de Nutrição. 2003; 16: 365-386. doi: 10.1590/S1415-52732003000400001.

36. Santos RF. Vendas fiadas e outras práticas creditícias na economia colonial - Minas Gerais, século XVIII. Revista Angelus Novus. 2012; 4: 4-21.

37. Bem Lignani J, Sichieri R, Burlandy L, Salles-costa R. Changes in food consumption among the Programa Bolsa Família participant families in Brazil. Public Health Nutrition. 2010; 14(5): 785792. doi: 10.1017/S136898001000279X.

38. Assunção VK. et al. Comer mais e melhor: os impactos do programa bolsa famílias na alimentação de famílias de pescadoras artesanais de Pernambuco. Amazônica. 2012; 4 (2): 336-353.

39. Save the children. Making Cash Count: Lessons from cash transfer schemes in east and southern Africa for supporting the most vulnerable children and households. Save the Children UK, Help Age International and Institute of Development Studies, 2005. Disponível em: <https://www.ids.ac.uk/files/MakingCashCountfinal.pdf>. Acesso em: 20 out. 2015.

40. Castro HCO, Walter MIMT, Santana CMB, Stephanou MC. Percepções sobre o Programa Bolsa Família na sociedade brasileira. Opinião Pública, 2009; 15(2): 333-355. doi:10.1590/S010462762009000200003.

41. Ibase. Repercussões do Programa Bolsa Família na Segurança Alimentar e Nutricional das famílias beneficiadas. IBASE: Documento síntese, 2008.

42. Canesqui AM. Mudanças e permanências da prática alimentar cotidiana de famílias de trabalhadores. In. Canesqui, AM, Garcia, RW. D (Org.) Antropologia e nutrição: um diálogo possível. Rio de Janeiro: Editora FIOCRUZ, 2005.

43. Canesqui AM. A qualidade dos alimentos: análise de algumas categorias da dietética popular. Revista de Nutrição. 2007; 20(2): 203-216. doi: 10.1590/S1415-52732007000200010.

44. Philippi ST, Latterza AR, Cruz ATR, Ribeiro LC. Pirâmide alimentar adaptada: guia para escolha dos alimentos. Revista de Nutrição. 1999; 12(1): 65-80. doi: 10.1590/S1415-52731999000100006. 